Rodríguez López, Ramona.

Técnico Superior de Investigación de la Universitat Politècnica de València.

Departament d'Escultura. Grupo de investigación Laboratorio de Luz.

\title{
Aproximación a los medios computacionales y generativos en la práctica artística: "S/T, serie nature code" instalación interactiva y "Travesía" proyección audiovisual y recitación poética.
}

TIPO DE TRABAJO:

Comunicación.

PALABRAS CLAVE:

Arte generativo, software, instalación, proyección, recitación poética.

KEY WORDS:

Generative art, software, installation, projection, poetic recital.

\section{RESUMEN.}

Planteamos la indagación en las técnicas digitales y computacionales, mediante la experimentación y el análisis que conforma la práctica artística, centrándonos en el arte generativo y el sonido, estableciendo nuestro foco de interés en las relaciones que se establecen entre lo visual y lo sonoro, llevándolo al terreno subjetivo y reinterpretando su sentido.

La instalación interactiva "S/T, serie nature code" y la proyección audiovisual y recitación poética "Travesía", suponen un primer acercamiento al arte computacional, mezclando propiedades de los distintos medios y técnicas. Nuestra intención es crear relaciones que conecten ideas, que llevadas al ámbito expositivo puedan interactuar con el público, formando parte del proceso de la obra de manera cognitiva y emocional.

La instalación "S/T, serie nature code", realizada a partir de un ejercicio con "Processing", fue presentada en la Muestra Pam! 16 y en la exposición colectiva "sobresaturados" en el Círculo de Bellas Artes, comisariada por Pepe Miralles.

"Travesía" se trata de una propuesta multidisciplinar que fusiona proyección audiovisual y recital poético. Tuvo lugar en la nueva librería Ramón Llull, situada en el barrio del Carmen, con motivo de la presentación del libro de poemas de la escritora Lola Andrés.

\section{ABSTRACT.}

We pose the inquiry in the digital and computational technicians, by means of the experimentation and the analysis that conforms the artistic practice, centring us in the generative art and the sound, establishing our focus of interest in the relations that establish among the visual and the audible, spending it to the subjective terrain and reinterpreting his sense.

The interactive installation "S/T, series nature code" and the audiovisual projection and poetic recitation "Travesía", suppose a first approach to the computational art, mixing properties of the distinct means and technical. Our intention is to create relations that connect ideas, wich in the exhibition space interact with the public, forming part of the process of the work in a cognitive and emotional way.

The installation "S/T, series nature code", made from an exercise with "Processing", was presented in the Sample Pam! 16 and in the collective exhibition "sobresaturados" in the Círculo de Bellas Artes, curated by Pepe Miralles. "Travesía" Treats of a multidisciplinary proposal that merges audiovisual projection and poetic recital. It took place in the new bookshop Ramón Llull, situated in the neighbourhood of Carmen, with motive of the presentation of the book of poems of the writer Lola Andrés. 


\section{CONTENIDO.}

\section{INTRODUCCIÓN.}

La evolución de las técnicas digitales y computacionales ha dado paso a nuevas formas de producción que se ven amplificadas en el espacio de internet. Según el análisis de Martín Prada, (...) "a mediados de los años 90 muchos artistas comenzaron a hacer de Internet el ámbito de investigación principal de sus obras y su contexto de actuación específico." ${ }^{1}$ Internet ha propiciado también el acercamiento a músicos y a artistas de software como medio de producción, favoreciendo el desarrollo de propuestas perceptivas cada vez más complejas, creadas con algoritmos que se basan en los sistemas generativos propios de la naturaleza, actuando como procesos autónomos y procesuales, y que, en algunos casos, implementan comportamientos propios de la inteligencia artificial. El arte computacional y generativo está dando una nueva dimensión al trabajo de artistas que implementan funciones novedosas en sus obras, usando bases de datos para crear sistemas de visualización, aletoriedad y secuenciación de objetos electrónicos, etc. Algunos ejemplos los encontramos en las obras de Daniel Canogar, la que lleva como título "Ripple" trata de una proyección en la que se fusionan unos 500 vídeos de la página del País, realizada con un algoritmo que transforma los datos.

El contexto artístico parece que se está haciendo eco de la deriva digital en ferias de arte como "Arco", dando cabida a propuestas de arte generativo como la pieza "Portrait on the fly" de Christa Sommerer y Laurent Mignonneau, ganadora del "Premio BEEP de Arte Electrónico" $2016^{2}$. Otros eventos en los que se exhibe el trabajo de artistas que reflexionan o emplean la tecnología son la "Mobile Week Barcelona", su programación cuenta con actividades en formato de diálogos para abordar el impacto de la transformación digital, además de la exhibición de obras que muestran una visión sobre la digitalización y sus repercusiones tanto locales como globales.

La cibercultura produce cada vez más imágenes y aplicaciones que van sobrepoblando los portales de internet, frente a esta saturación se plantea el reciclaje, el uso de material procedente de la red como un acto de ecología visual ${ }^{3},($...) ya no se trata de producir "obras" sino de prescribir sentidos" ${ }^{4}$ como argumenta Joan Foncuberta. De esta realidad con tanta diversidad de medios que se influencian mutuamente subyacen cambios susceptibles de estudio: semiológicos, paradigmas y posibilidades estéticas, lingüísticas e interactivas.

\section{ACERCAMIENTOS AL ARTE COMPUTACIONAL Y GENERATIVO.}

En el presente artículo vamos a analizar dos obras que suponen un primer ensayo en la tarea de analizar las posibilidades que los medios digitales ofrecen, en especial los basados en el software y lo computacional, no solamente por su naturaleza generativa, sino también el análisis del medio en sí mismo, su carácter performativo. Nos interesa investigar y reflexionar sobre los cambios estéticos, lingüísticos e interactivos que devienen a través de estos medios, así como el papel del sonido en relación a las imágenes, con una metodología basada en la experimentación artística que trata de conectar ideas, espacios y la figura del espectador. Otros aspectos aparejados a la investigación es la búsqueda de estrategias de expresión, incorporando material procedente de internet como forma de reciclaje visual, dando una nueva lectura a las imágenes ya existentes, cuestionando los límites de la autoría creativa y el concepto de originalidad y de arte. De este modo, el papel del artista queda desplazando al trabajo selección y recombinación, sirviendo a su afán de hacer preguntas y buscar respuestas.

\section{"S/T, SERIE NATURE CODE".}

Instalación interactiva exhibida en la MUESTRA PAM!16 realizada en la Facultad de Bellas artes de san Carlos. UPV, del 21 al 28 de abril de 2016.

Descripción técnica: Serigrafía de 60X90 centímetros, pantalla de 70X41 centímetros, ordenador y webcam.

La obra forma parte de la serie "nature code", experimento realizado con el programa Processing (software que funciona con lenguaje de programación para proyectos multimedia), manipulando los ejemplos y tutoriales que dispone este software tanto en sus librerías como en youtube. En sintonía con la filosofía de las comunidades de desarrolladores de software libre que comparten sus algoritmos y ofrecen todo tipo de tutoriales y manuales, Daniel Shiffman, creador de Processing, tiene un numeroso archivo de ejemplos, ha escrito

\footnotetext{
${ }^{1}$ MARTÍN PRADA, J. Prácticas artísticas e internet en la época de las redes sociales. Op. Cit., p. 9.

2 http://www.coleccionbeep.org/wp-content/uploads/2016/12/Ganadores_Premio_ARCOMadrid-BEEP-es_2016.pdf \{Consulta: 10 marzo 2017\}

${ }^{3}$ FONCUBERTA, J. La furia de las imágenes. Notas sobre la postfotografía. Op. Cit., p. 39.

En el punto tres del decálogo propuesto por Juan Foncuberta habla de la responsabilidad del artista en la que se impone una ecología de lo visual.

${ }^{4}$ Ibid. Punto uno del decálogo.
} 
el libro "Nature of Code", centrado en estrategias de programación y técnicas de simulación basadas en los procesos naturales que permiten obtener resultados visuales muy sofisticados. ${ }^{5}$
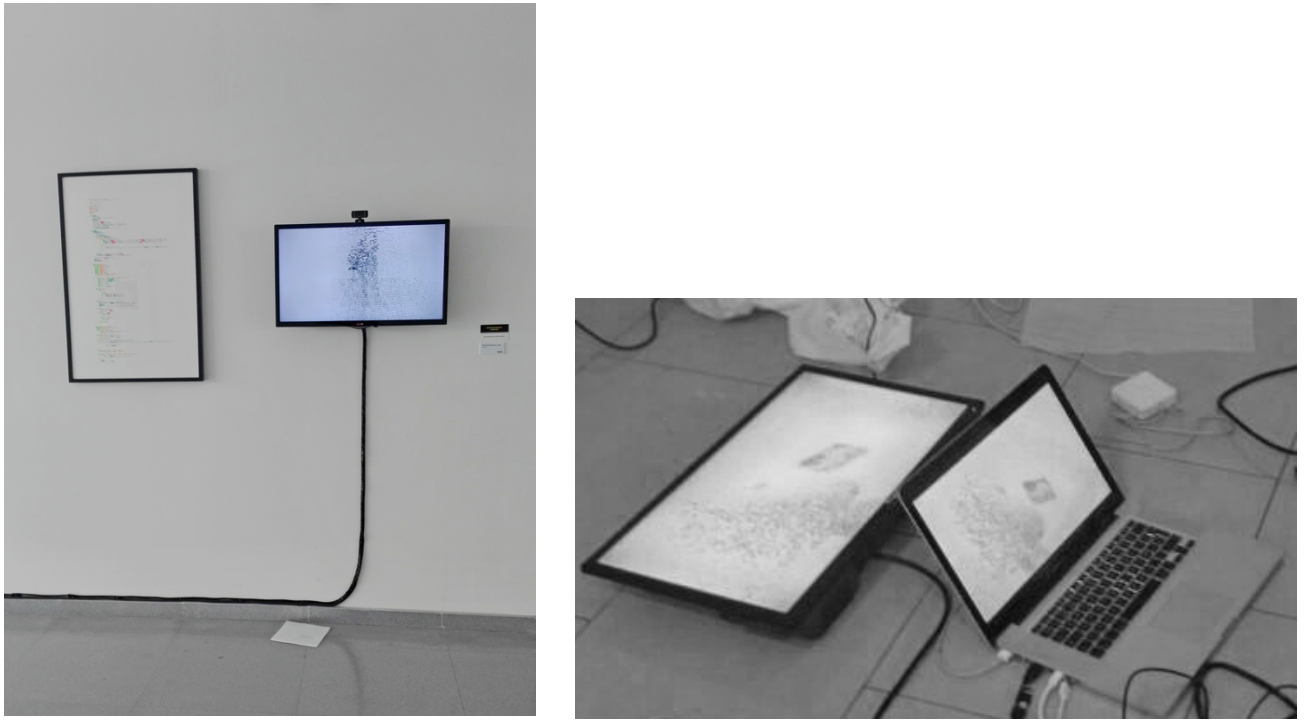

llustraciones 1, 2. Detalle de "S/T, serie nature code" en la muestra PAM! 16.

La obra está formada por un monitor y una webcam conectados a un ordenador que inicializa un sketch realizado con Processing, y una serigrafía montada en un soporte o cuadro en la que se muestra el código con el que se ha programado el sketch ${ }^{6}$.

Relación de imagen y sonido. El ordenador procesa la imagen pero no el sonido. En la obra se escucha el sonido accidental que se produce en la propia sala, como John Cage planteaba en su pieza "4,33". La atención se centra en lo visual y en la acción del espectador, sin modificaciones sonoras que puedan desviar el sentido.

El código y su escritura, impresión serigráfica, estarcido. El tema del cuadro es el código fuente, las instrucciones del sketch que se genera a partir de una variante del lenguaje Java. La idea de visualizar el código es una referencia a los "Live Coder"7:

"Como se explica en el Mani esto TOPLA, la idea no es que la audiencia sepa leer el lenguaje de programación que el live coder utiliza, y, si supiera hacerlo, tampoco se espera que esté atenta y siga el desarrollo de la música a través de la lectura de la progresión de las líneas de código: "no es necesario que el público entienda el código para poder apreciarlo, como no es necesario saber tocar guitarra para apreciar a un guitarrista tocando". 8

Nuestra intención al mostrar el código es la de desvelar los mecanismos por los cuales el ordenador produce sus ilusiones, cómo la realidad es manipulada por el software, llevando la escritura de los medios digitales al estatus de motivo para su reproducción, de la pantalla al soporte físico. Tratamos de Introducir un nuevo enfoque, estableciendo relaciones entre técnicas artísticas, lo digital frente a lo impreso. Serigrafía: impresión y transferencia de imágenes mediante el método del estarcido o estampación. Una de las artes más importantes en todos los aspectos gráficos de la publicidad y la industria con "ramificaciones que abarcan campos tan dispares como la impresión de circuitos eléctricos y la transferencia de dibujos a botellas de cristal". "La impresión del texto que está realizada en tinta de color negro es sometida a un destacado con marcadores o rotuladores de algunos elementos del código, en el lenguaje de programación el color sirve de distintivo para determinadas funciones o agentes. Aprovechamos esta circunstancia para incorporar el color a la obra y dar más ritmo visual al tiempo que se crea una cierta secuencialidad.

\footnotetext{
${ }^{5}$ Información obtenida de la web de Daniel Shiffman. http://shiffman.net/books/ \{Consulta: 20 febrero de 2017\}.

${ }^{6}$ Sketch, es el nombre que reciben los archivos realizados con el software Processing. Constan de instrucciones a base de código.

7 Término que utilizan músicos y programadores que realizan exhibiciones en tiempo real utilizando software.

${ }^{8}$ DI PRÓSPERO, C. Live coding. Arte computacional en proceso. Contenido. Arte, Cultura y Ciencias Sociales. Op. Cit., p. 3.

${ }^{9}$ MARA, T. Manual de serigrafía. Op. Cit., p. 7.
} 

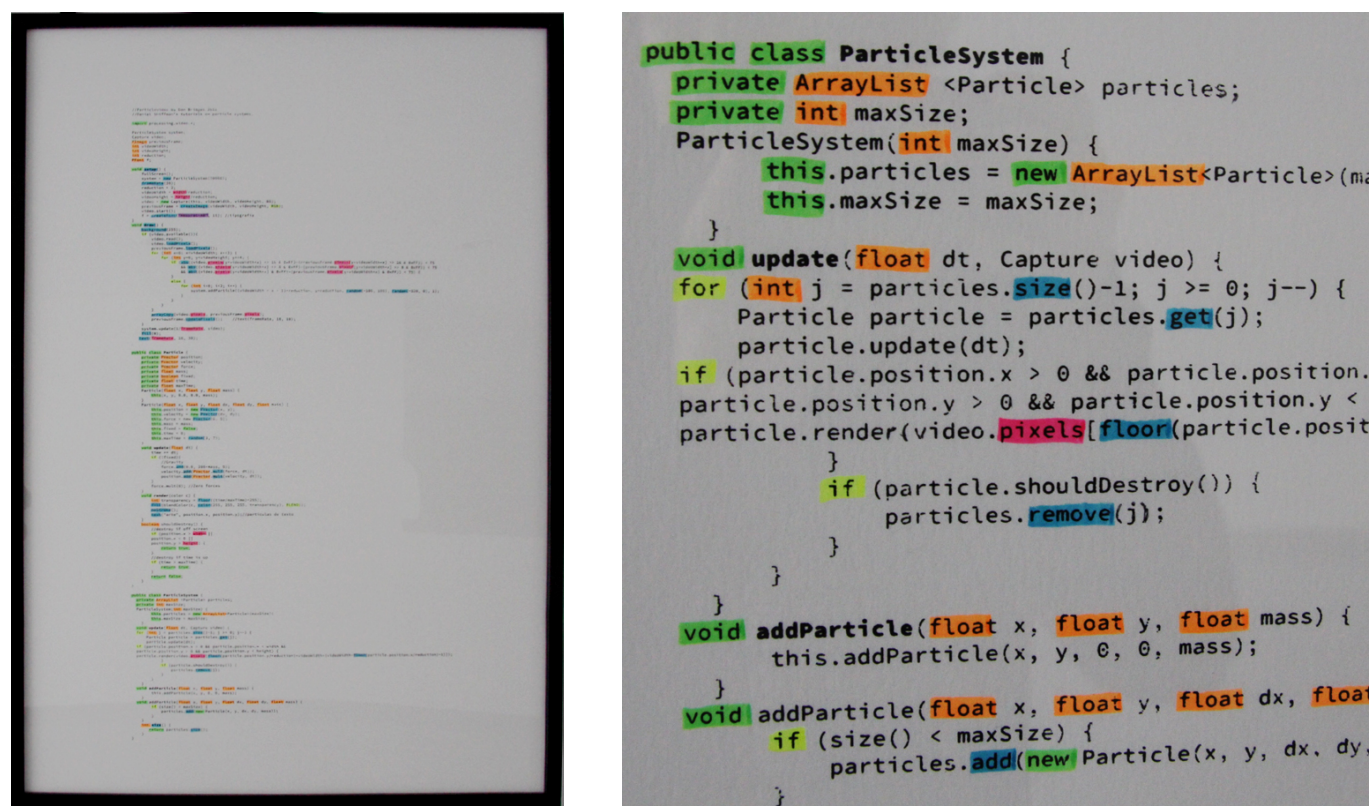

llustraciones 3, 4. Imagen de la serigrafía exhibida en Pam! 16.

Interacción. El espectador es el elemento que produce un cambio. El movimiento crea imagen, si no hay movimiento la imagen desaparece, cae con la fuerza de la gravedad. La pieza interactiva registra la imagen del espectador compuesta de píxeles con la palabra "ARTE". Cuando el espectador deja de moverse las palabras caen y desaparece la imagen. Aborda cuestiones sobre la fugacidad de las imágenes en un contexto de novedad constante en el que cada instantánea tiene fecha de caducidad, es sustituida rápidamente por una nueva. La imagen del espectador en el monitor hace referencia a la cuestión narcisista de la sociedad contemporánea, estableciendo distintas relaciones conceptuales: el espectador y su retrato creado a partir de la palabra arte (cualquiera puede ser artista), la pantalla como espejo y el movimiento como metáfora de la necesidad de evolucionar y adaptarse a lo nuevo en la cibercultura por miedo a desaparecer.
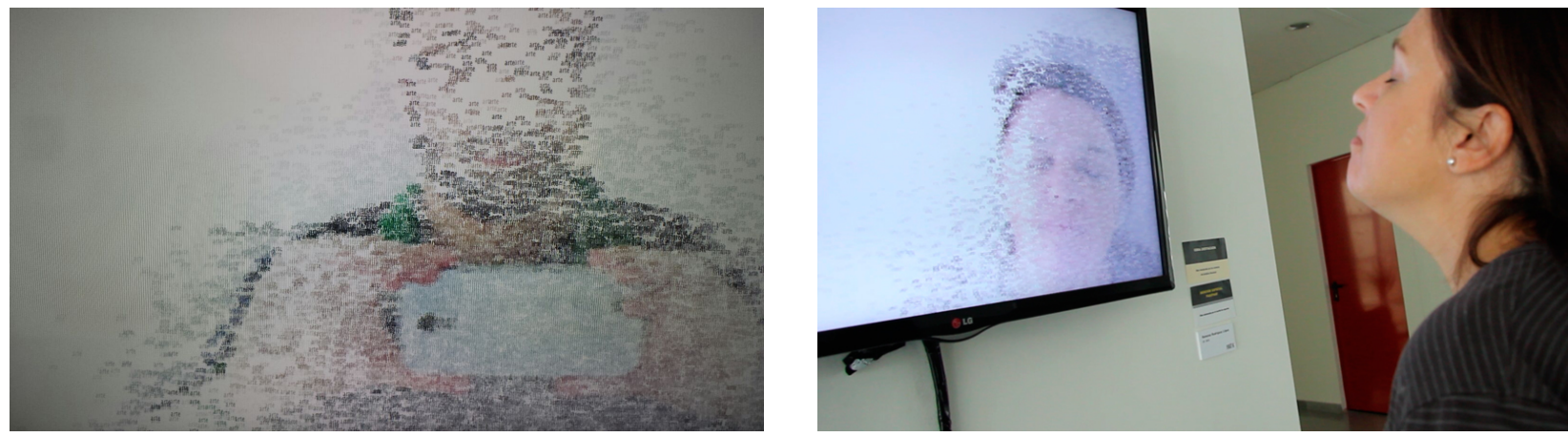

llustraciones 5, 6. Imagen tomada por Luis Lisbona a través del móvil frete a la pieza "S/T, serie nature code". PAM!16. Rostro y reflejo de Teresa Pensado interactuando con la obra.

"SOBRESATURADOS." Exposición colectiva realizada en el Círculo de Bellas Artes de Valencia, comisariada por Pepe Miralles. Artistas: Lara López Sanz, Mara Ases, Carmelo Gabaldón, Teresa Pensado y Ramona Rodríguez. 
La temática de la exposición es la sobresaturación contemporánea a la que estamos sometidos.

"La sobre/actividad y la sobre/saturación visual son elementos naturalizados en nuestra vida diaria, estas son las nuevas maneras impuestas y autoimpuestas de volvernos ciegos voluntarios; ciegos de nosotros mismos. Apropiación fragmentación - indefinición - superposición." ${ }^{10}$

Exhibición de la instalación "Diecisietemil yoes". La obra se modifica para adaptarla al nuevo espacio, se cambia el título. La serigrafía es sustituida por una impresión digital en papel con un tamaño de $4 \times 1$ metro. El monitor con la webcam se ubica dentro del papel, como un pop-up entre el código escrito. El algoritmo se modifica reemplazando la palabra "ARTE" por la palabra "YO" estableciendo un cambio de sentido, una relación con el Narciso contemporáneo que trata de inscribirse en la realidad a través de los selfies y el volcado de su privacidad en las redes sociales. En el código se intercalan comentarios que hacen alusión al contexto de internet como elementos de reflexión, un ejemplo: "compartimos nuestra intimidad" escrito en el apartado del código que implementa la webcam. La pantalla funciona como un espejo y registra la imagen del espectador, su doble compuesto por la palabra "YO" multiplicada por tantos pixeles como contiene la imagen dando un resultado plástico de carácter pictórico "una pintura del yo (...)" $)^{11} \mathrm{El}$ texto y sus significados, la palabra "Yo" es la que genera nuestro reflejo, los yoes que nos componen hablan de las identidades múltiples que nos representan y que circulan en la red.
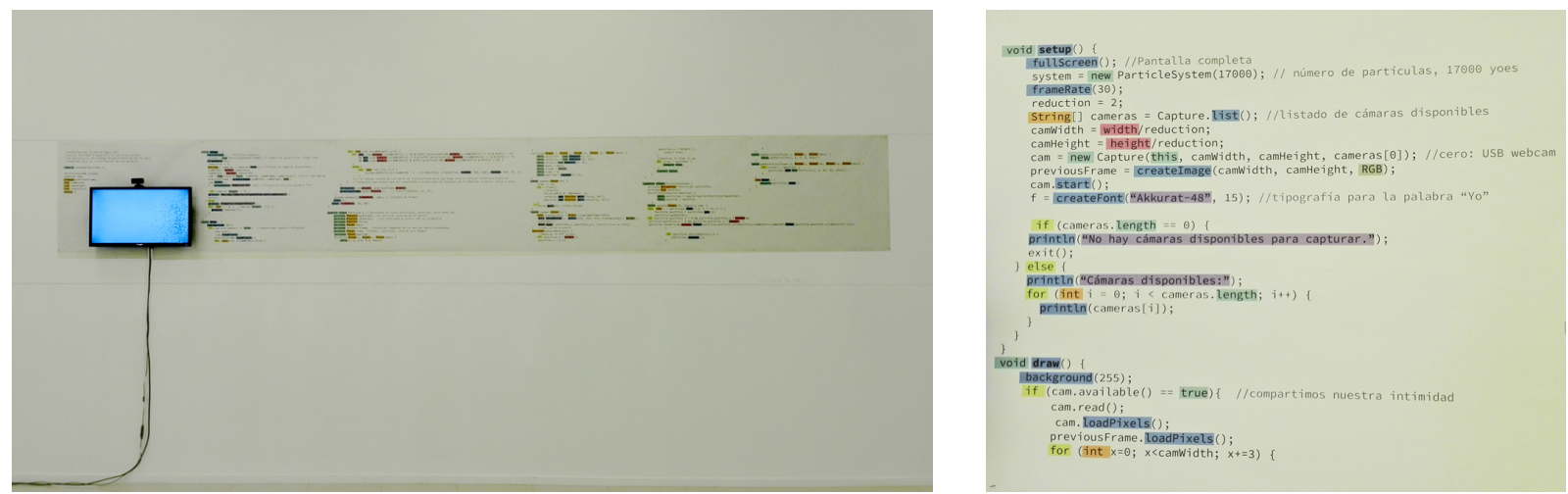

Ilustraciones 7, 8. Imágenes de la instalación “Diecisietemil yoes” en el Circulo de Bellas Artes de Valencia.

\section{"TRAVESÍA"}

Proyección audiovisual y recitación poética realizada en la Renovada Ramon Llull (Barrio del Carme, calle Corona 5), el 1 de diciembre de $2016 .^{12}$

Vídeo Full HD: 18’30 minutos

La obra surge a partir de la propuesta de colaboración en la presentación del libro de poesía "Travesía" escrito por Lola Andrés. En él se habla del cuerpo, del instinto y la conciencia, se sitúa "en la órbita nietzscheana de la escritura del cuerpo, de la restauración del instinto con la finalidad de comprender y comprenderse." ${ }^{13}$

\footnotetext{
${ }^{10}$ Fragmento del texto de presentación de la exposición Sobresaturados. Traducido del valenciano al castellano. http://www.cbbaav.es/wpcontent/uploads/2014/01/Texto-Presentaci\%C3\%B3n-Sobresaturados-2.pdf \{Consulta: 11 febrero 2017\}.

${ }^{11}$ FONCUBERTA, J. La furia de las imágenes. Notas sobre la postfotografía. Op. Cit., p. 39. Citado Lewis Mumford. 182. Técnica y civilización. Madrid. Alianza.

${ }^{12}$ Información ofrecida por la editorial. http://edicionescontrabando.com/presentaciones.php?id=254 (Consulta: 2 marzo 2017).

${ }^{13}$ ANDRÉS, L. Travesía. Op. Cit., p. 11. (Prólogo de Luís Falcó)
} 

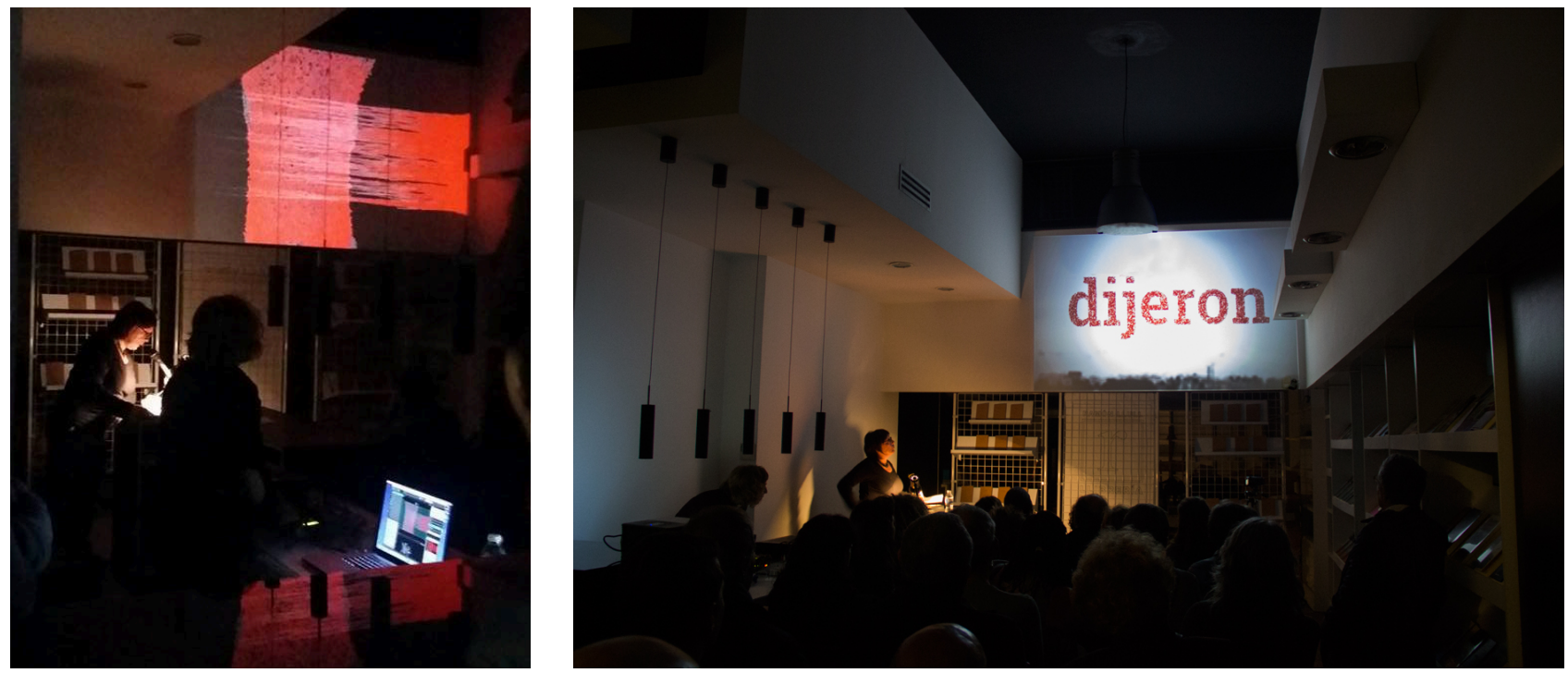

llustraciones 9, 10. Imágenes de la presentación de "Travesía", 1 de diciembre de 2016, Librería Ramón Lluch.

Una de las modalidades más habituales en la presentación de un libro de poesía es la del recital: una selección de poemas pasan del soporte escrito a la liturgia de la voz, su modulación sonora, entrando en juego la expresividad del tono y la gestualidad del cuerpo. El espectador permanece en un lugar de escucha, sentado. Hay un trabajo cognitivo emocional, la voz propone imágenes, metáforas y símbolos que el cerebro tiene que descifrar. "Travesía" estaría en el límite de la polipoesía y la poesía fonética, aunque trabaja con lo sonoro prevalece el significado de la palabra que funciona como trama y urdimbre del tejido escénico. Lo que se busca es generar una experiencia en el espectador, el sonido, la imagen y el cuerpo son el envoltorio que atrapa al asistente y sobre el que se cobija un tiempo dado, el tiempo que dura el relato.

El tema. El libro trata sobre una especie de murciélago mutante que inicia un trayecto en el que se suceden acontecimientos que lo van mermando, restando hasta desaparecer; un poco a contracorriente con las historias de crecimiento personal en las que se va ampliando la consciencia y el enriquecimiento personal. La obra se estructura en seis partes en las que se despliegan varias voces, la autora establece un diálogo consigo misma, puesta en escena de una conciencia dialógica en la que se pronuncian las diferentes voces: el narrador, el yo desdoblado, el participe, la voz en off.

\section{Capítulos:}

1. La pregunta. El narrador dice lo que ocurre.

2. Signos de partida. Se expresa cómo quisieron hacer la travesía. Hay indicaciones de peligro.

3. La matanza. Pánico, estruendo, mutilación.

4. El estruendo. Se recrudece el instinto que reaparece en un lugar de muerte.

5. Adentro. El personaje se esconde.

6. Sin respuesta. Repliegue hacia el interior, interés por los detalles de las pequeñas cosas, el sonido de las hojas.

\section{Apartado visual.}

Las estrategias discursivas del vídeo están fundamentadas en la narración poética y el diálogo entre las voces, la figura del narrador se alterna entre la imagen grabada y la presencia del cuerpo, el tiempo congelado en un bucle y el gesto performativo en tiempo real. Grabación previa de la poeta recitando los pasajes en prosa que contiene cada capítulo. La obra está pensada para emitirse en un espacio con audiencia, una actuación en directo donde combinar presencia y representación, cambiando la posición y la escala del cuerpo representado que se va transformando, poblado de elementos que lo modifican, el color, el rostro velado, líneas que lo 

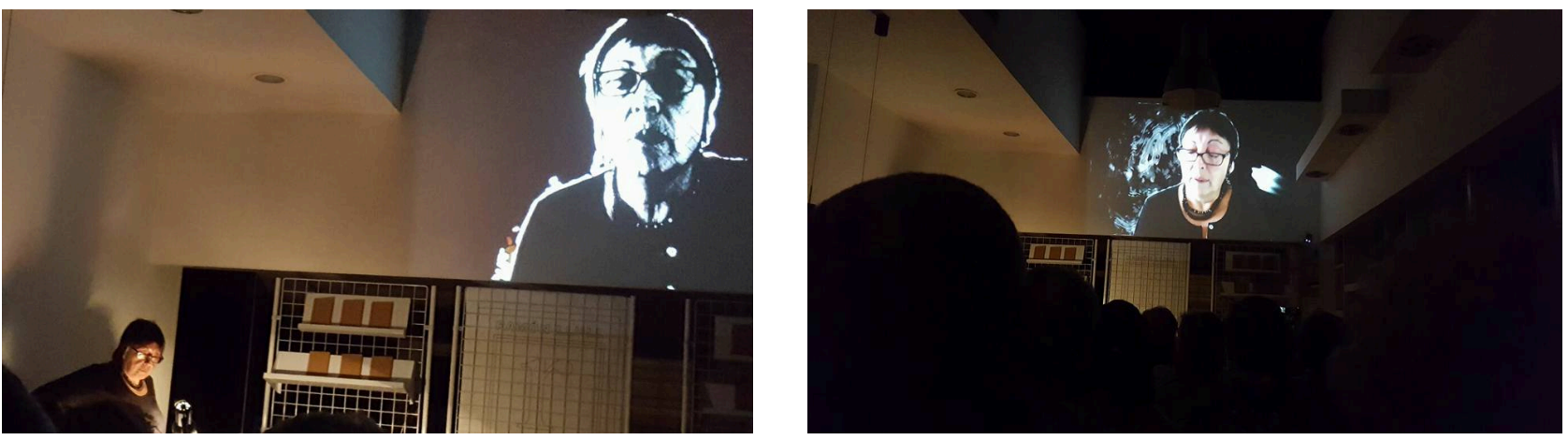

Ilustraciones 11, 12. Imágenes la presentación de "Travesía" en las que se muestra:

la posición de la proyección y el lugar de la poeta recitando.

El tiempo y el espacio son dislocados mediante el collage de secuencias visuales de distintas tipologías, desde videos de paisajes, animación, fragmentos de piezas de arte generativo y fotografía. La procedencia de estos elementos también es diversa, va desde producciones propias (documento de la autora recitando, entre otros) a la "adopción" ${ }^{14}$ de material existente en internet, haciendo una labor de recolección y selección que posteriormente "samplear" ${ }^{15}$ para sugerir estados emocionales. En el proceso de postproducción hay un trabajo de transformación mediante la mezcla y manipulación, con filtros y herramientas que ayudan en el montaje a crear la sensación de continuidad en los fragmentos que componen el vídeo final. En la secuencia de la "Matanza" se ensamblan imágenes de guerra y mutilación tomadas de la red, momentos de la historia que corresponden a la guerra de Vietnam, el holocausto nazi, el drama de los refugiados y otros desastres mundiales. El tiempo del pasado convive con el presente, intención crítica que trata de activar la consciencia recordando que no han desaparecido las matanzas. El drama global vivido de forma cotidiana a través de los medios de comunicación se suma al dolor de las perdidas personales.

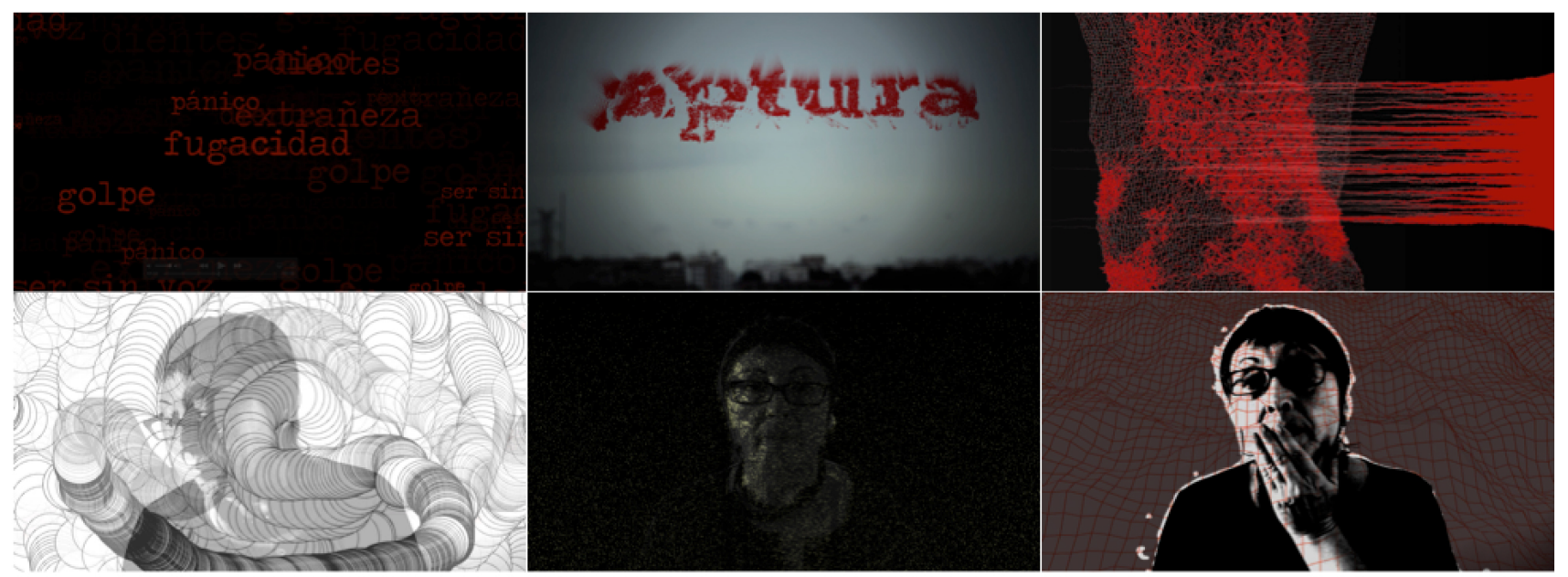

Ilustración 13. Imagen con varios frames del vídeo "Travesía” generadas a partir de la fusión con capturas de sketches de Processing (algoritmos de partículas, random de palabras y movimiento, etc.).

\footnotetext{
${ }^{14}$ Nos decantamos por el término de adopción del que habla Joan Foncuberta frente al de apropiación. "Apropiarse quiere decir "captar", mientras que adoptar quiere decir "declarar haber escogido". En la adopción prevalece el acto de elegir, no de desposeer."

FONCUBERTA, Joan. 2016. La furia de las imágenes. Notas sobre la postfotografía. Barcelona: Galaxia Gutenberg S.L. Op. Cit., p 60. ${ }^{15}$ MARTÍN PRADA, J. Prácticas artísticas e internet en la época de las redes sociales. Op. Cit., p. 176.
} 
El software utilizado en la creación, manipulación y edición de vídeo e imágenes: After Effects, Adobe Premiere, Processing, Photoshop, Jitter.

\section{Apartado sonoro.}

La voz grabada y la voz en directo procesada por el micrófono dan estructura a la propuesta, marcan el ritmo, la expresividad y el sentido del relato. Todo empieza desde lo sonoro, esperando la escucha atenta al intervalo del cuerpo y el discurso.

"La voz, corporeidad del habla, se sitúa en la articulación del cuerpo y el discurso, y en ese espacio intermedio es donde se va a efectuar el movimiento de vaivén del acto de escuchar" ${ }^{16}$

El sonido electrónico acompaña a la voz, tiene una función de sutura con lo que se expresa, de ligazón con lo emocional. La recreación de la atmósfera psicológica se realiza mediante el sampleado de texturas sonoras que varían según el pasaje de la presentación, más contundentes en "La matanza" o sutiles en "Adentro", con matices de rasgaduras, soniquetes, efectos de aleteo, lluvia, etc. Todo está en función de la escucha, para que sea un acto de introspección lo más inmersivo posible, potenciando lo que se ve y lo que cuenta la voz.

El material sonoro utilizado procede de producciones propias, grabaciones de paisajes sonoros y composiciones realizadas con osciladores y síntesis modular. Los programas utilizados son Ableton, Max MSP, Reason y Adobe Audition.

\section{CONCLUSIONES.}

Los objetivos de las prácticas descritas en el presente artículo eran la puesta en escena de ideas mediadas por la tecnología computacional o de tipo generativo, postproducidas y manipulada para analizar el propio medio, el código de la máquina, la imagen y el sonido digital. El proceso ha servido para conocer las derivas de sentido que se establecen en la combinación de ideas, la influencia del sonido sobre la imagen y viceversa, la actitud del espectador frente a los códigos visuales planteados.

Escuchando las opiniones de los asistentes a Pam! 16, "Sobresaturados" y "Travesía", hemos percibido la empatía y el interés por lo que las obras planteaban, la actitud del espectador señala que la revolución digital está cada vez más incorporada en lo cotidiano y en el imaginario colectivo.

“Las imágenes articulan pensamiento y acción. Compete a la filosofía y a la teoría, pero también al arte, descifrar con urgencia su condición maleable y mutante." ${ }^{17}$

\section{FUENTES REFERENCIALES.}

ANDRÉS, L. Travesía. Valencia: Ediciones Contrabando, 2016.

ARNS, I. El código como acto de habla performativo Artnodes: revista de arte, ciencia y tecnología, Issue 4, 2005.

BLANCHARD, P. [et al.]. Música y nuevas tecnologías : perspectivas para el siglo XXI. Barcelona: L'Angelot, D.L., 1999.

BREA, J. L. Las tres eras de la imagen: imagen-materia, film, e-image. Madrid: Akal, D.L., 2010.

BARTHES, R. Lo obvio y lo obtuso: Imágenes, gestos, voces. Barcelona, etc.: Paidós, 1986.

DI PRÓSPERO, C. Live coding. Arte computacional en proceso. Contenido. Arte, Cultura y Ciencias Sociales. N. 5, 2015.

DELEUZE, G. L'image-temps, Minuit, París, (trad. esp.: La imagen-tiempo. Estudios sobre cine 2, Paidós, Barcelona, 1985.

\footnotetext{
${ }^{16}$ BARTHES, R. Lo obvio y lo obtuso: Imágenes, gestos, voces. Op. Cit., p. 252.

${ }^{17}$ FONCUBERTA, J. La furia de las imágenes. Notas sobre la postfotografía. Op. Cit., p. 10.
} 
III CONGRESO INTERNACIONAL DE INVESTIGACIÓN EN ARTES VISUALES :: ANIAV 2017 :: GLOCAL [codificar, mediar, transformar, vivir] http://dx.doi.org/10.4995/ANIAV.2017.6366

ESCOFFET, E. Poesia, sonoritat i electrònica / Poésie, sonorité et électronique; Poesía, sonoridad y electrónica; Poetry, tone and electronic music. Costa, Lis ; Temps d'Educació, , Issue 42, 2012.

FONCUBERTA, J. La furia de las imágenes. Notas sobre la postfotografía. Barcelona: Galaxia Gutenberg S.L., 2016.

GALANTER, P. Entre dos fuegos: el arte-ciencia y la guerra entre ciencia y humanidades. Artnodes: revista de arte, ciencia y tecnología. Issue 11, pp.33-38, 2011.

MARA, T. Manual de serigrafía. Barcelona: Blume, 1994.

MARTÍN PRADA, J. Prácticas artísticas e internet en la época de las redes sociales. Madrid: Akal. 2012.

CHION, Michel . La audiovisión: Introducción a un análisis conjunto de la imagen y sonido. Barcelona etc.: Paidós Ibérica, $1993,2004$. 